\title{
Clinical outcome of patients with differentiated thyroid cancer and raised antithyroglobulin antibody levels: a retrospective study
}

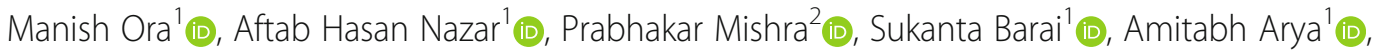

Prasanta Kumar Pradhan ${ }^{1}$ (D) and Sanjay Gambhir ${ }^{1^{* *}}$ (i)

\begin{abstract}
Background: Thyroglobulin (Tg) is a specific tumor marker for differentiated thyroid cancer (DTC). However, in the presence of an antithyroglobulin antibody (TgAb), it becomes unreliable. The purpose of the study was to assess the long-term outcome of DTC patients with raised TgAb.

Method: In a retrospective study, we included patients with DTC who had raised TgAb following total thyroidectomy. We excluded patients with persistently raised $\operatorname{Tg}(\geq 1 \mathrm{ng} / \mathrm{ml})$ or radioiodine avid disease. Serial $\mathrm{TgAb}$ levels, excellent response (ER), incomplete response (IR), and anatomical recurrence were evaluated.

Results: A total of seventy-six patients were included in the study. Patients with IR had higher baseline TgAb $(1071.27 \pm 1216.17$ vs. $99.61 \pm 91.29 \mathrm{IU} / \mathrm{ml}, p<0.001)$ and central compartment lymph node metastases $(70.8 \%$ vs. $46.4 \%, p=0.035)$ in comparison to those in the ER group. In the first follow-up, 64 (84.2\%) patients had a stable or fall in the TgAb (0 to $-98.3 \%)$. Sixty-eight patients received high-dose radioiodine therapy (RIT). Out of these, 59 (86.5\%) had transient, and 51 (75\%) had a long-term fall in TgAb. After a follow-up period of $58.74 \pm 26.26$ months, 63.2\% (48 out of 76) patients had IR. Nine (11.8\%) patients had a rising TgAb level (3.7-170.9\%) from baseline. Eleven patients underwent 18F-FDG PET/CT, and five of them demonstrated metabolically active recurrent disease. Three patients underwent cervical lymph nodes dissection. None of the patients died during the follow-up period.

Conclusion: High post-operative TgAb levels and central compartment lymph nodal metastases are risk factors for IR. RIT leads to a significant fall in the TgAb in these patients. The low level of raised TgAb is associated with an excellent outcome. Patients with recurrences had very high baseline TgAb >1000 IU/ml. Raised TgAb was associated with good clinical outcomes and not associated with increased mortality.
\end{abstract}

Keywords: Differentiated thyroid cancer, Serum antithyroglobulin antibody, Radioiodine therapy, Recurrence

\section{Introduction}

Differentiated thyroid cancer (DTC) is the most common of the endocrine cancers. It accounts for $3.1 \%$ of all malignancies globally, with an age-standardized

\footnotetext{
* Correspondence: gaambhir@yahoo.com

${ }^{1}$ Department of Nuclear Medicine, SGPGIMS, Lucknow, India

Full list of author information is available at the end of the article
}

incidence of 7.4/ 100,000 people. However, because of the excellent 5 and 10 years survival rate in comparison to other solid malignancies, it is the fifth most prevalent cancer in the world [1].

Treatment of DTC consists of total thyroidectomy or lobectomy. Surgery is followed by evaluation of postoperative disease status. It consists of a diagnostic

(C) The Author(s). 2021 Open Access This article is licensed under a Creative Commons Attribution 4.0 International License, which permits use, sharing, adaptation, distribution and reproduction in any medium or format, as long as you give appropriate credit to the original author(s) and the source, provide a link to the Creative Commons licence, and indicate if changes were made. The images or other third party material in this article are included in the article's Creative Commons licence, unless indicated otherwise in a credit line to the material. If material is not included in the article's Creative Commons licence and your intended use is not permitted by statutory regulation or exceeds the permitted use, you will need to obtain permission directly from the copyright holder. To view a copy of this licence, visit http://creativecommons.org/licenses/by/4.0/. The Creative Commons Public Domain Dedication waiver (http://creativecommons.org/publicdomain/zero/1.0/) applies to the data made available in this article, unless otherwise stated in a credit line to the data. 
whole-body radioiodine scan (WBS), serum thyroglobulin $(\mathrm{Tg})$, and antithyroglobulin antibody (TgAb) assay [2]. The need for radioiodine therapy (RIT) depends on the patient's disease stage and risk factors [2]. Serial Tg and TgAb assays and neck ultrasonography (USG) with or without WBS are currently the mainstays of postoperative surveillance in patients with DTC.

$\mathrm{Tg}$ is the specific tumor marker of the DTC and is a critical investigation to identify patients with residual or recurrent disease. Tg is only produced by thyroid tissue or well-differentiated thyroid cancer tissue, so serum Tg level helps detect recurrent or residual disease in DTC patients who have undergone total thyroidectomy and RIT. However, in the presence of $\mathrm{TgAb}, \mathrm{Tg}$ measurement becomes unreliable and may fail to identify patients with significant residual or recurrent tumors $[2,3]$. The variability in $\mathrm{TgAb}$ assays may also result in falsely negative $\mathrm{TgAb}$ levels [3]. It is associated with a misleadingly low serum $\mathrm{Tg}$ due to the presence of the antibodies that the assay could not detect [3]. Both Tg and TgAb assays may be affected by heterophilic antibodies $[4,5]$.

Nearly $20 \%$ of DTC patients show circulating TgAb [3]. It is commoner in patients with autoimmune Hashimoto's thyroiditis (HT). The presence of TgAb should be suspected when the pathology indicates the background HT. [6] Some studies have suggested an association between autoimmune thyroid disease and papillary thyroid cancer. However, the prognostic significance of this finding is not well understood [3, 7-9]. Destruction of normal follicular thyrocytes or neoplastic cells may reduce or even eradicate $\mathrm{TgAb}$ by removing the antigenic stimulus [10]. However, persistent or increasing serum TgAb level in DTC patients during their followup is a recurrent/persistent disease marker. Several authors have reported the association between DTC aggressiveness and $\operatorname{TgAb}$ with discordant results [11-16]. However, the long-term clinical outcome and clinical significance of the raised TgAb are not very well studied.

This retrospective single-center study aims to evaluate the DTC patient with raised serum TgAb titers after surgery. We aim to assess the changes in the TgAb levels after radioiodine ablation and the patients' long-term clinical outcome.

\section{Material and methods}

\section{Patients selection}

This retrospective study included DTC patients treated in the Nuclear Medicine department between January 2005 and December 2018. All patients underwent total thyroidectomy at our institution or a regional hospital. Patients underwent central compartment neck dissection (CCLND) in advanced primary tumors, biopsy-proven lymph node metastases, or suspicious neck USG findings preoperatively.
All patients with biopsy-proven metastatic lateral cervical lymphadenopathy underwent lateral neck lymph node dissection (LLND). The patients were included in the study after considering the following inclusion and exclusion criteria (Fig. 1).

\section{Inclusion criteria}

1. A raised serum TgAb titer at the initial postoperative assay after total thyroidectomy and before WBS or RIT

2. Stimulated serum $\mathrm{Tg}$ level less than $1 \mathrm{ng} / \mathrm{dl}$ in first follow up (after 6 months)

3. A negative WBS scan in the first follow-up

4. Adequate clinical follow-up data for at least 12 months is available.

\section{Exclusion criteria}

1. Patients with both elevated $\mathrm{Tg}(\geq 1 \mathrm{ng} / \mathrm{dl})$ and $\mathrm{TgAb}$ in follow-up

2. Patients with anaplastic carcinoma or with a poorly differentiated variant of papillary thyroid carcinoma (such as the insular, tall cell variant)

3. Patients who were lost to follow up

4. Patients have positive WBS in follow-up (persistent iodine avid local or distant metastatic disease).

\section{Radioiodine ablation}

All patients were prepared by withdrawing thyroid hormone replacement for 1 month. Radioiodine was given for WBS to all patients with TSH levels above $50 \mathrm{mIU} /$ L. Stimulated serum Tg (Immunoradiometric assays with functional sensitivities up to $0.2 \mathrm{ng} / \mathrm{mL}$ ), TgAb (radioimmunoassay RIA) were measured in all the patients. Radioiodine therapy (RIT) was administered to all patients with positive WBS. After that, all patients received hormonal suppression therapy to keep a TSH level according to the risk category and response to therapy during the follow-up according to the American Thyroid Association (ATA) guidelines [2].

\section{Evaluation of treatment response and clinical management during follow-up}

All patients were evaluated 6 months after the RIT for early response assessment. The initial response to therapy was assessed by serum $\mathrm{Tg}$ and $\mathrm{TgAb}$ measurements and WBS. After the first follow-up, patients were reassessed with stimulated/suppressed serial Tg and TgAb measurements, neck USG with or without WBS every 6-12 months. In patients with very high or rising $\mathrm{TgAb},{ }^{18} \mathrm{~F}$ - FDG PET-CT was done. Ultrasound-guided fine-needle aspiration cytology (FNAC) was performed in all patients with 


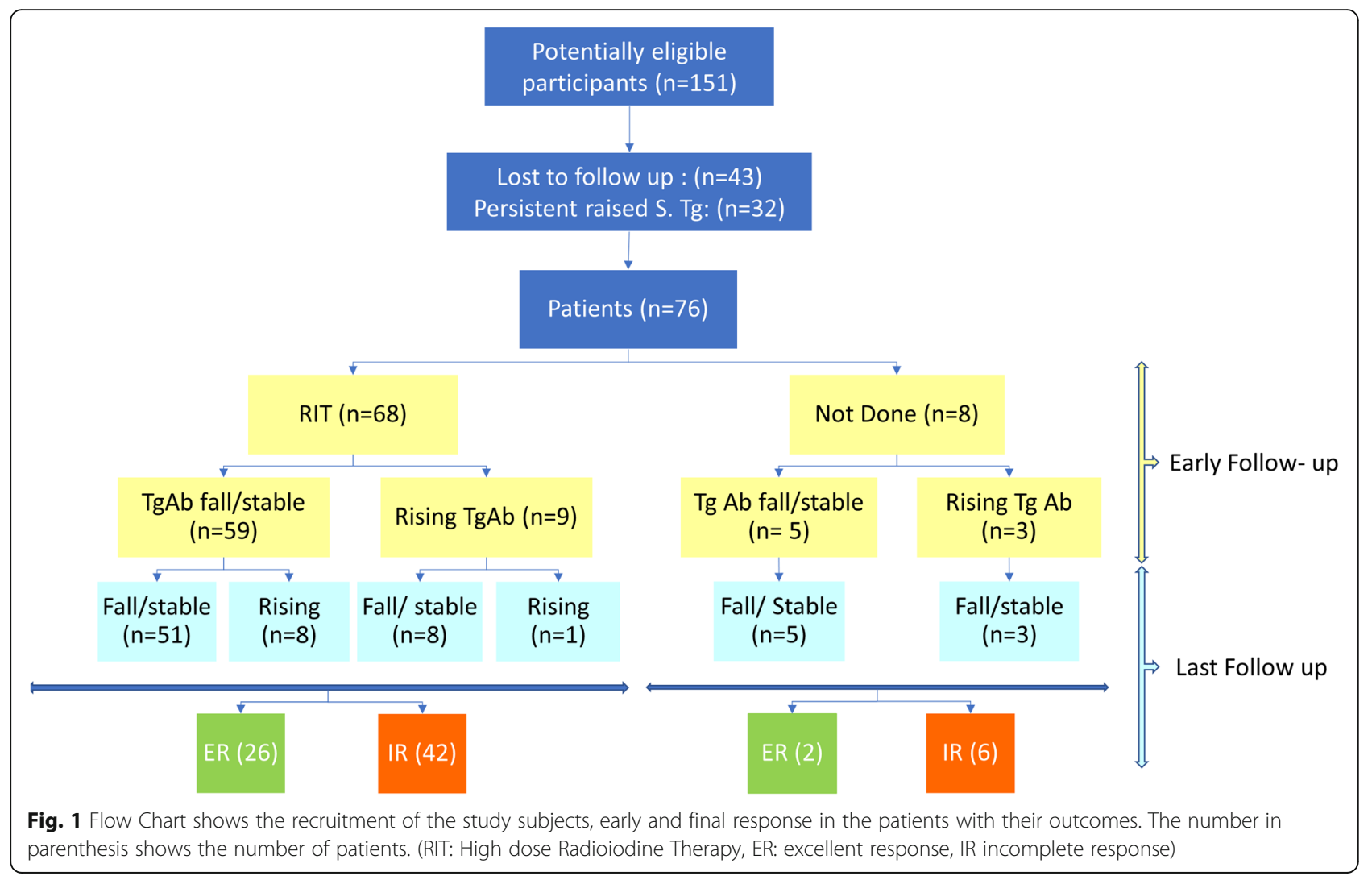

suspicious neck lesions. Patients with recurrent disease are referred for surgery.

\section{Definition of the outcome}

1. A stimulated $\mathrm{Tg}<1 \mathrm{ng} / \mathrm{ml}$, absence of $\mathrm{TgAb}$, no uptake on WBS in follow-up was defined as an excellent response (ER).

2. A negative WBS stimulated serum $\mathrm{Tg}<1 \mathrm{ng} / \mathrm{mL}$ with persistent/declining TgAbwas considered an indeterminate response.

3. A negative WBS, stimulated $\mathrm{Tg}<1 \mathrm{ng} / \mathrm{mL}$ with increasing TgAbwas considered as a biochemical incomplete response (BIR) [2].

In -follow-up, patients were reclassified as ER if patients with BIR or intermediate response showed a stimulated $\mathrm{Tg}<1 \mathrm{ng} / \mathrm{ml}$, undetectable TgAb, and no evidence of suspicious disease on WBS or USG. For this study, patients with rising (BIR) or stable/ declining $\mathrm{TgAb}$ (indeterminate response) were considered incomplete response (IR) groups. Any rise in the level of TgAb in the follow-up compared to the baseline was considered as rising TgAb. Falling TgAb was considered if patients had any falls in the level of the TgAb.

\section{Data collection and analysis}

Clinical data included patient demographics, tumor characteristics (histological features, baseline tumor stage), treatments (the type of surgery, RIT), laboratory and imaging finding (serial serum $\mathrm{Tg}$ and TgAb levels, and ${ }^{18} \mathrm{~F}$-FDG PET-CT), and outcome (disease status and cause of death if applicable). Patients were stratified using the eighth edition of the American Joint Committee on Cancer/International Union against Cancer (AJCC/UICC) staging system [17].

\section{Statistical analysis}

The normality of the continuous variables was established. A variable was considered normally distributed when the $Z$ value of the skewness was within \pm 3.29 . The normality of the continuous variable was expressed as means \pm standard deviation while categorical variables as frequencies (\%). Independent samples t-test was used to compare the means between the two groups. Chisquare tests (or Fisher exact test) were performed to test the association between two categorical variables. The receiver operating characteristics (ROC) curve was used to calculate the area under the curve (AUC) and appropriate cutoff value with corresponding sensitivity and specificity for the detection of IR by TgAb levels. Data analysis was done on the Statistical Package for Social 
Sciences (IBM Corp. Released 2015. IBM SPSS Statistics for Windows, Version 23.0. Armonk, NY: IBM Corp).

\section{Results}

\section{Baseline characteristics}

The study included a total of seventy-six patients (female: $63,82.8 \%$ ). A baseline summary of patient characteristics, including demography, primary surgery, histopathology details, and biochemical parameters, are presented in Tables 1 and 2. The mean age of presentation was $35.71 \pm 14.01$ years, with a range of $10-75$ years. Nearly three fourth $(77.6 \%)$ and a half $(46.1 \%)$ of the patients underwent CCLND and LLND, respectively. The classical variant of papillary carcinoma was the most common (90.8\%) histopathological variant, followed by the follicular variant. One-third (32.9\%) of the patients had metastasis limited to the central compartment, and another one-third (35.5\%) also had lateral neck lymph nodal involvement. Baseline (median, range) serum $\mathrm{Tg}$ and TgAb were $0.27(0.2-121) \mathrm{ng} / \mathrm{dl}$ and 166.5 (304000) $\mathrm{IU} / \mathrm{ml}$, respectively.

\section{Radioiodine therapy and early response assessment (Fig.} 1)

The WBS was positive in $68(89.5 \%)$ of the patients. Fifty-three patients only had the remnant. Thirteen patients had involvement of cervical lymph nodes on WBS. Of these 13 patients, three also had mediastinal lymph node involvement, and one had lung metastasis.. These patients received $66.05 \pm 41.12 \mathrm{mCi}$ of $\mathrm{RIT}\{1.11-5.55$ GBq (30-150 mCi of 131I)\}. Eight patients with negative WBS did not receive RIT. In the first follow-up after 6 months, $64(84.2 \%)$ patients had a stable or fall in the $\mathrm{TgAb}$, ranged from 0 to $-98.3 \%$. Of these, twenty (26.3\%) patients had ER. However, at the first follow-up, twelve patients (15.8\%) had a rising TgAb level (1.95334\%). (Figs. 1 and 2).

Long term follow up and change in the TgAb level (Figs. 1, 2 and 3)

Patients were in the long-term follow-up (58.74 \pm 26.26 months). TgAb became undetectable (ER) in a total of 28 patients. The rest of the $48(63.2 \%)$ patients were in IR, with TgAb level ranges between 22 and $8000 \mathrm{IU} / \mathrm{ml}$. Out of these 48 patients, 21 patients had a TgAb titer less than $100 \mathrm{IU} / \mathrm{mL}$. Out of 59 patients who had fallen TgAb after RIT, 51 patients had persistent falling levels in the follow-up. Eight patients had a rise (3.7-334.4\%) in the TgAb after RIT. None of the patients in the ER group showed reappearance of the TgAb. At the time of the final analysis, only nine (11.8\%) patients had a rising TgAb level (3.7-170.9\% from the baseline). Out of these, only two had the recurrent disease. Total ten patients had moderately raised TgAb (500-1000 IU/ml). None of them had recurrent disease.

\section{Structural recurrence and role of 18F FDG PET-CT}

A total of $11(14.47 \%)$ patients underwent 18F FDG PET-CT (diagnostic CT along with intravenous contrast agent) for the significantly raised (510-4000 IU/ml) stable or rising TgAb. All the patients with the TgAb less than $1000 \mathrm{IU} / \mathrm{ml}$ had no lesions on the PET-CT. Out of these, five patients demonstrated metabolically active lesions. Thyroid bed recurrence, lymph node involvement, and metastatic lung nodules were noted in 1, 5, and 2 patients. The standardized uptake value (SUVmax) of cervical lymph nodes was 3.8-8.8. All patients underwent USG guided FNAC and showed results suggestive of disease recurrence. Three patients underwent lymph nodes dissection for the recurrent disease. HPE was suggestive of lymph

Table 1 Descriptive characteristics of the study patients $(N=76)$

\begin{tabular}{llll}
\hline Variables & Mean & Median & Percentile (Q1, Q3) \\
\hline Age (years) at diagnosis & $35.71 \pm 14.01$ & 34 & 25,45 \\
Time between Surgery and RIT & $3.64 \pm 1.65$ & 3.0 & $3,4.8$ \\
RIT (mCi) & $66.05 \pm 41.12$ & 60.0 & 30,100 \\
Tg Baseline ${ }^{a}$ & $5.98 \pm 16.78$ & 0.27 & $20,2.80$ \\
Tg after RIT & $0.66 \pm 1.24$ & 0.20 & $0.20,0.79$ \\
TgAb (baseline) & $713.29 \pm 1073.6$ & 166.50 & $70,675.3$ \\
TgAb after RIT & $420.23 \pm 830.56$ & 103.0 & $10,339.5$ \\
TgAb (\% change, Baseline-early follow up) & $-34.29 \pm 68.62$ & -47.57 & $-78.97,-11.96$ \\
TgAb (final) & $450.42 \pm 1185.20$ & 53.0 & $10,245.5$ \\
TgAb (\% change, Baseline-last follow up) & $-52.62 \pm 53.16$ & -73.48 & $-86.90,-33.40$ \\
Follow up Duration (months) & $58.74 \pm 26.26$ & 55 & $42.30,71.8$ \\
\hline
\end{tabular}

RIT High dose Radiodiodine Therapy, Tg Serum Thyroglobulin, TgAb Serum Antithyroglobulin antibody

${ }^{\text {a }} \mathrm{Tg}$ level expressed in $\mathrm{ng} / \mathrm{dl}$

${ }^{\mathrm{b}} \mathrm{TgAb}$ level expressed in IU/ml 
Table 2 Characteristic of the patient's groups based on TgAb response $(N=76)$

\begin{tabular}{|c|c|c|c|c|}
\hline Variables & $\begin{array}{l}\text { Incomplete response } \\
(N=48,63.2 \%)\end{array}$ & Excellent response $(N=28,36.8 \%)$ & $\begin{array}{l}\text { Total } \\
(N=76)\end{array}$ & $P$-value \\
\hline${ }^{\mathrm{a} A g e}$ (Years) & $37.75 \pm 14.96$ & $32.21 \pm 11.66$ & $35.71 \pm 14.01$ & 0.077 \\
\hline Sex (Female) & $40(83.3)$ & $23(82.1)$ & $63(82.9)$ & 0.990 \\
\hline \$TAB (baseline) & $1071.27 \pm 1216.17$ & $99.61 \pm 91.29$ & $713.29 \pm 1073.55$ & $<0.001$ \\
\hline \multicolumn{5}{|c|}{ Surgery } \\
\hline CCLND (Yes) & $41(85.4)$ & $18(64.3)$ & $59(77.6)$ & 0.033 \\
\hline LLND (Yes) & $27(56.3)$ & $8(28.6)$ & $35(46.1)$ & 0.020 \\
\hline \multicolumn{5}{|c|}{ Histopathology } \\
\hline HPE CCLND (Yes) & $34(70.8)$ & $13(46.4)$ & $47(61.8)$ & 0.035 \\
\hline HPLND (Yes) & $20(41.7)$ & $6(21.4)$ & $26(34.2)$ & 0.073 \\
\hline \multicolumn{5}{|l|}{ Pathology } \\
\hline PCT & $43(89.6)$ & $26(92.8)$ & $69(90.8)$ & 0.991 \\
\hline PCT FV & $3(6.3)$ & $2(7.1)$ & $5(6.6)$ & \\
\hline FCT & $1(2.1)$ & $1(3.6)$ & $2(2.6)$ & \\
\hline \multicolumn{5}{|l|}{ T stage } \\
\hline 1 & $3(6.3)$ & $6(21.4)$ & $9(11.8)$ & 0.228 \\
\hline 2 & $9(18.8)$ & $4(14.3)$ & $13(17.1)$ & \\
\hline 3 & $7(14.6)$ & $5(17.9)$ & $12(15.8)$ & \\
\hline$x$ & $29(60.4)$ & $13(46.4)$ & $42(55.3)$ & \\
\hline \multicolumn{5}{|l|}{ N Stage } \\
\hline 0 & $7(14.6)$ & $13(46.4)$ & $20(26.3)$ & 0.010 \\
\hline N1a & $16(33.3)$ & $9(32.1)$ & $25(32.9)$ & \\
\hline $\mathrm{N} 1 \mathrm{~b}$ & $22(45.8)$ & $5(17.9)$ & $27(35.5)$ & \\
\hline$x$ & $3(6.3)$ & $1(3.6)$ & $4(5.3)$ & \\
\hline \multicolumn{5}{|l|}{ AJCC staging } \\
\hline 1 & $39(81.3)$ & 27 (96.4) & $66(86.8)$ & 0.0345 \\
\hline 2 & $7(14.6)$ & $1(3.6)$ & $8(10.5)$ & \\
\hline 3 & $2(4.1)$ & $0(0)$ & $1(2.7)$ & \\
\hline \multicolumn{5}{|l|}{ WBS findings } \\
\hline Positive & $42(87.5)$ & $26(92.8)$ & $68(89.5)$ & 0.703 \\
\hline Remnant only (Yes) & $38(79.1)$ & $21(75.0)$ & $59(77.6)$ & 0.519 \\
\hline LN on WBS & $10(20.8)$ & $7(25.0)$ & $17(22.4)$ & 0.674 \\
\hline LN Metastases ${ }^{\mathrm{b}}(\mathrm{Yes})$ & $39(81.5)$ & $17(60.7)$ & $56(73.7)$ & 0.005 \\
\hline
\end{tabular}

LN Lymph node, TgAb antithyroglobulin antibody, CCLND central compartment lymph node, LLND lateral compartment lymph node, HPE histopathology, PCT papillary carcinoma thyroid, FV follicular variant, FCT follicular carcinoma thyroid, AJCC American joint committee for cancer, WBS whole-body radioiodine scan $p<0.05$ is significant and are shown in bold fonts, All parenthesis are percentages

andependent samples t-test used \$ Mann Whitney U test. Chi-square test / Fisher exact test was used

${ }^{b} \mathrm{LN}$ metastases are either lymph node metastases on HPE or LN on WBS

nodal metastasis in these patients. None of the patients died during follow-up.

\section{Predictors of incomplete response after surgery:}

\section{Univariate analysis (Table 2)}

In the IR group, the patients were older than patients in the ER group ( $37.75 \pm 14.96$ vs. $32.21 \pm 11.66, P=0.077$ ), although the difference was not statistically significant.
The IR group had higher baseline TgAb levels $(1071.27 \pm 1216.17 \mathrm{IU} / \mathrm{ml}$ vs. $99.61 \pm 91.29 \mathrm{IU} / \mathrm{ml}, \quad p<$ 0.001), CCLND (85.4 vs $64.3 \%, p=0.033)$, LLND (56.3\% vs $28.6 \%, p=0.002)$, and central compartment lymph node metastases $(70.8 \%$ vs. $46.4 \%, p=0.035)$ in comparison to the ER group. No combination of variables was significantly associated with IR or ER on multivariate binary logistic regression analysis. 


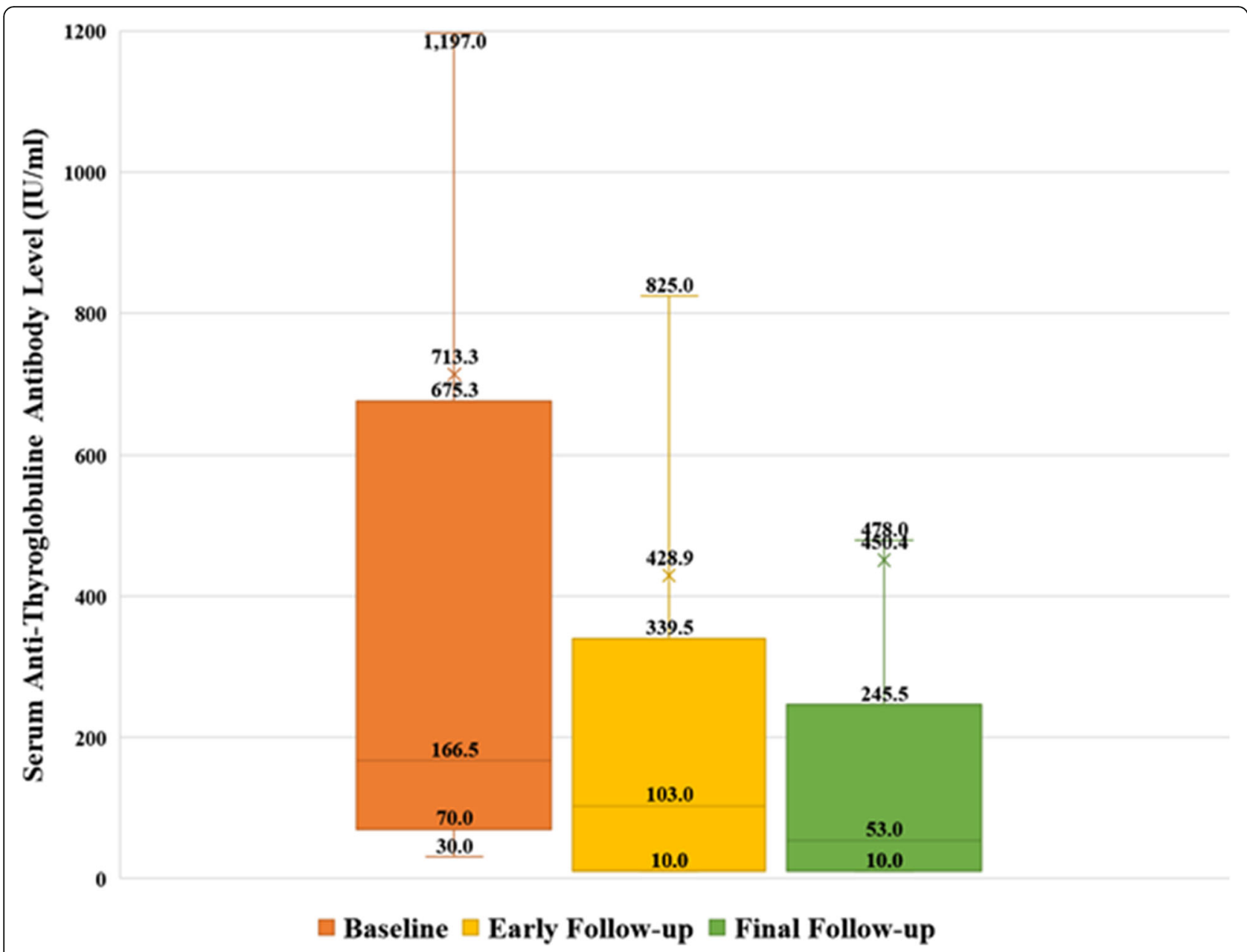

Fig. 2 The box plot shows a trend in Antithyroglobulin antibody levels in the baseline, early, and final follow-up. Note that all the outlier data are not shown

\section{Prognostic value of pre-ablative baseline $\mathrm{TgAb}$ for incomplete and excellent response}

ROC curve was drawn to find the diagnostic accuracy of the TgAb level to identify the IR and ER. AUC was 88.3\% (95\% CI $=81.1-95.6, p<0.001)$ (Fig. 4). From all the available cut-off values of TgAb level, three cut-off values i.e. at $\mathrm{TgAb} \leq 241.5 \mathrm{IU} / \mathrm{ml}$ (Sensitivity $=89.3 \%$, Specificity $=68.7 \%), \quad \mathrm{TgAb} \leq 158 \mathrm{IU} / \mathrm{ml} \quad$ (Sensitivity $=78.6 \%$, Specificity $=69.7 \%$ ), and $\operatorname{TgAb} \leq 89 \mathrm{IU} / \mathrm{ml}$ (Sensitivity = $71.4 \%$, Specificity $=87.5 \%$ ) were considered as the best cut-off value.

\section{Discussion}

The study included a total of seventy-six patients. A large proportion of the patients underwent CCLND and LLND. Lymph nodal metastases were common in our cohort and were noted in 56(73.7\%) patients. Baseline (median, range) serum $\mathrm{Tg}$ and $\mathrm{TgAb}$ were 0.27 (0.2121) $\mathrm{ng} / \mathrm{dl}$ and 166.5 (30-4000) IU/ml, respectively. The WBS was positive in 68 (89.5\%) of the patients, and they received RIT. After 6 months, 84.2\% of patients had a stable or fall in the TgAb range from 0 to $-98.3 \%$, and twenty (26.3\%) had ER. After a follow-up (58.74 \pm 26.26 months), ER was noted in 28 patients. In the rest of the $48(63.2 \%)$ with IR, the TgAb level ranges from 22 to $8000 \mathrm{IU} / \mathrm{ml}$. Out of 59 patients who had fallen TgAb after RIT, 51 patients had persistent falling levels in the follow-up. A total of 11 patients underwent 18F FDG PET-CT. Five patients demonstrated metabolically active lesions, and three patients underwent cervical lymph nodes dissection. None of the patients died during follow-up. The IR group had higher baseline TgAb levels, CCLND, LLND, and central compartment lymph node metastases. The baseline $\mathrm{TgAb} \leq 241.5 \mathrm{IU} / \mathrm{ml}$ has excellent sensitivity (89.3\%) for predicting IR.

Long-term follow-up of DTC patients is required to detect recurrence. Serum Tg remains the cornerstone of the investigation. However, persistent $\mathrm{TgAb}$ may cause Tg levels to be variable. Approximately $20 \%$ of DTC patients and $10 \%$ of the general population show $\mathrm{TgAb}$ 


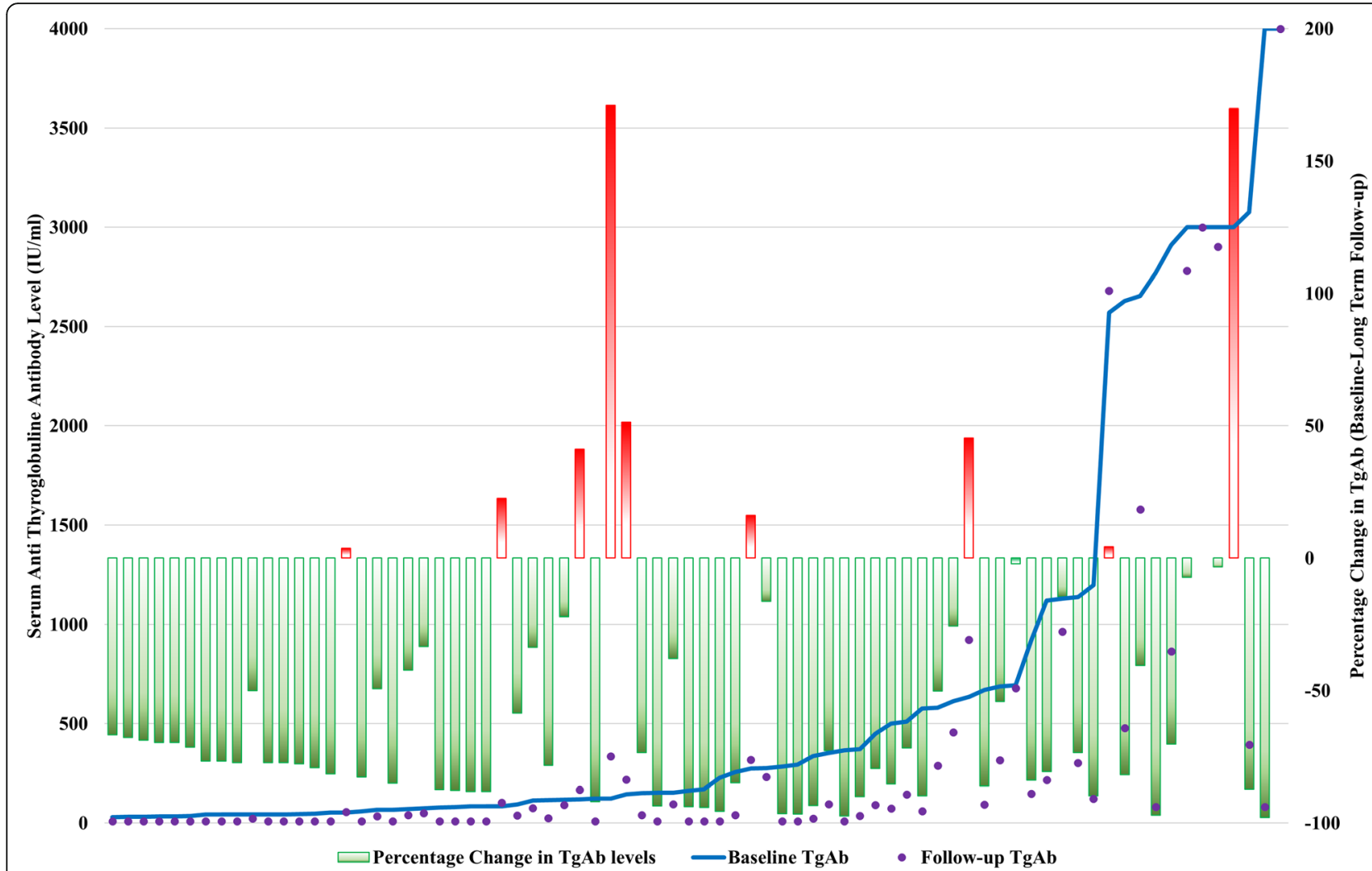

Fig. 3 Patients are shown as ascending baseline serum TgAb level (Primary Y-axis). The secondary Y-axis presents percentage change in the TgAb level from baseline to last follow-up (green bars: falling TgAb, Red Bars: rising TgAb). TgAb: Antithyroglobulin antibody

$[15,18]$. There may be an early transient decline in $\mathrm{TgAb}$ from increased formation and metabolic clearance of Tg-TgAb complexes formed by a rise in $\mathrm{Tg}$ with surgery [19]. Destruction of the follicles may lead to an acute increase in $\mathrm{Tg}$ antigen and production of TgAb. TgAb may rise or become detectable in response to thyroid surgeries, FNAC, biopsy, or RIT [15, 20-23]. After that, in the absence of a thyroid tissue mass and Tg antigen, TgAb concentrations decline over several months $[24,25]$. The median half-life of TgAb after surgery for DTC is 10 weeks [24]. We observed a transient rise in $\mathrm{TgAb}$ in comparison to baseline after RIT in 8 patients. All of them had a subsequent fall in the TgAb in the long-term follow-up.

Raised serum TgAb in DTC presents a unique clinical scenario and much concern to the patient and the physician. TgAb interference causes an underestimation of serum Tg when measured by IMA. However, Tg could be either under-or overestimation when measured by RIA. Minimal TgAb concentrations may interfere with Tg without being detected by a few methods. The interference is minimal when $\mathrm{Tg}$ (RIA) in the specimen is high and TgAb is low. However, it becomes significant when $\mathrm{Tg}$ is low and TgAb is high [3]. Rising TgAb levels after initial treatment are considered as a 'biochemical incomplete response' $[2,26]$. Several studies have demonstrated an increased risk of recurrence/persistent disease with a new appearance of $\mathrm{TgAb}$ or rising titers [14, 24, 27].

After surgery and RIT, the mean TgAb disappearance time is about 3 years $[24,25]$. A persistently low and declining $\operatorname{TgAb}$ concentration after the initial surgery does not always indicate recurrence [15]. It demonstrates the importance of long-term follow-up in this subset of patients. Our study did not find any structural recurrence in $27(35.52 \%)$ and $51(67.05 \%)$ patients with baseline TgAb levels less than 100 and $500 \mathrm{IU} / \mathrm{mL}$, respectively. However, recurrences were seen in $5(31.25 \%)$ patients with TgAb> $1000 \mathrm{IU} / \mathrm{mL}$. Kim et al. noted similar results and found that the recurrence rate was 18 and $1 \%$ for serum $\mathrm{TgAb}>100 \mathrm{U} / \mathrm{mL}$ and $\mathrm{TgAb} \leq 100 \mathrm{U} / \mathrm{mL}$, respectively [15]. We found that the baseline TgAb correlates with the patient's outcome (ER: $99.61 \pm 91.29$ and IR: 1071.27 $\pm 1216.17, p=0.001$ ). Similar observations were seen by a few but not by all previous authors $[16,28$, 29].

Our results confirm a favorable long-term outcome in patients with early normalization or significant fall in TgAb titers. Few authors have supported this finding [14-16]. In our study, 59 (86.8\%) patients had stable or 


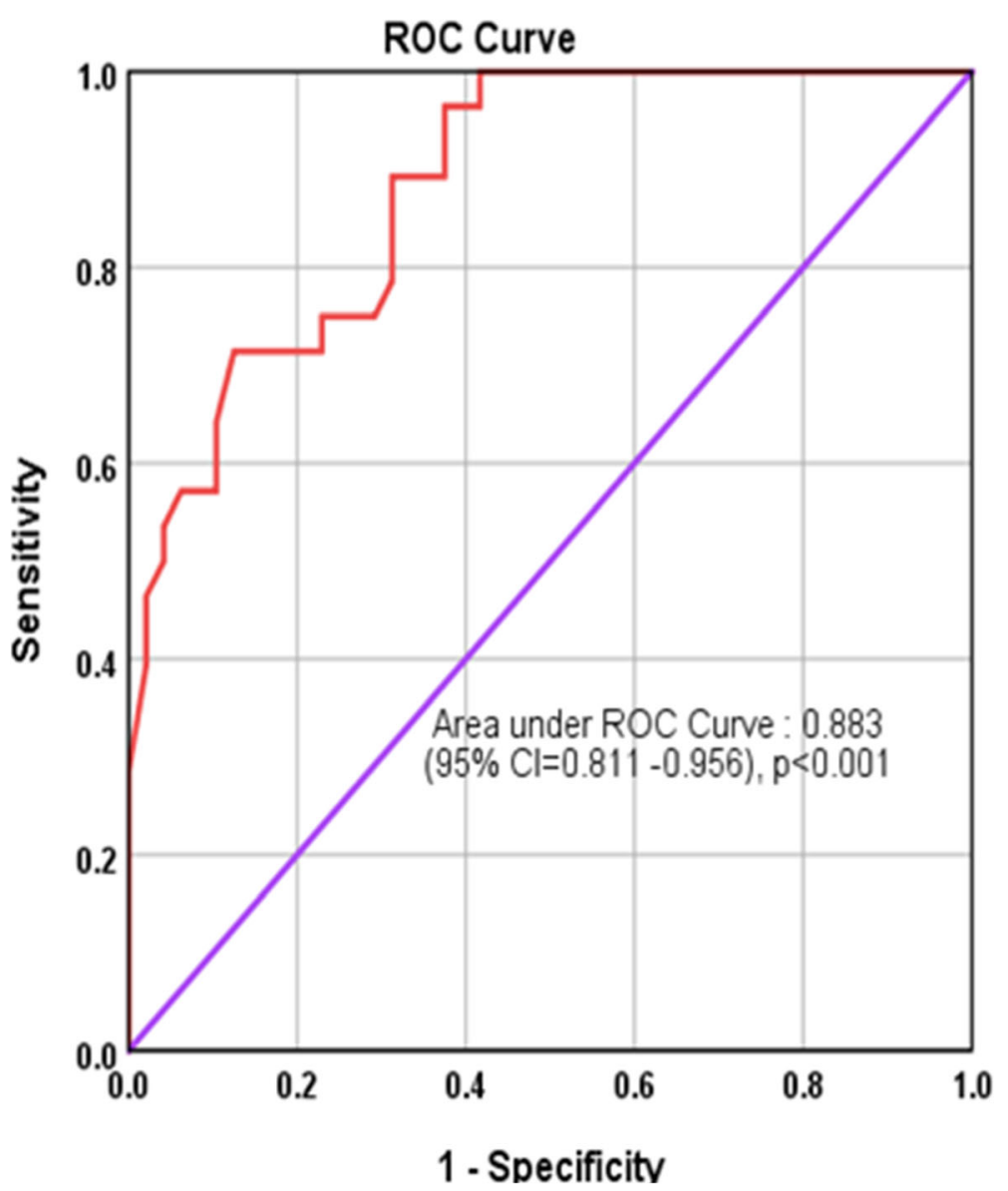

Fig. 4 ROC curve showing diagnostic accuracy of the baseline Antoithyroglobulin antibody level to detect the expected fall in TgAb during the follow-up

fell off (0 to -98.3\%) TgAb levels after RIT. Approximately one-third had an ER. Of these 59 patients, 51 (86.4\%) patients had a persistently low TgAb level in follow-up. None of them had a rising TgAb or recurrence in follow-up. It may be due to the eradication of functional thyroid cells, benign or malignant, eliminating the antigenic stimulus $[3,25]$. .Like our study, a previous study demonstrated that less than $1 \%$ of patients with 50-100\% decline in TgAb after RIT had a recurrence. However, 37\% of patients with rising TgAb and 19\% of patients in whom the fall was less than $50 \%$ had recurrences [15].

In our study, only five patients (6.5\%) had an anatomical recurrence in follow-up, similar to a study by Durante et al. [10]. However, the recurrences were much lower in comparison to other studies (13.6-49\%) [14, 15, 30]. This result may be due to different study populations. One of the primary inclusion criteria of our study was a negative follow-up WBS scan. This rules out the possibility of the residual normal or malignant iodine avid thyroid tissue. However, many previous studies did not have it as an inclusion criterion [10, 15, 16, 31]. It raises the possibility of minimal residual tissue in these studies that produced $\mathrm{Tg}$ and a persistent $\mathrm{TgAb}$. It could be an associated reason for high structural recurrence in those studies. Despite high but stable TgAb levels, many patients remained asymptomatic with no evidence of structural recurrence and did not require active interventions.

Our study found that the history of lymph node dissection and lateral compartment lymph nodal metastasis were significantly associated with IR $(45.8 \%, p=0.01)$. Like our observation, Tsushima et al. also showed that N1b lymph nodes metastases and recurrence were common in patients showing $<50 \%$ fall or rising $\mathrm{TgAb}$ in follow-up [30]. We found that the IR group had higher initial TgAb levels and TNM stages. However, the TNM stage was not a significant factor in multivariable regression analysis.

In a large meta-analysis consisting of 38 studies (10 648 patients), $23.8 \%$ of DTC patients had coexisting Hashimoto's Thyroiditis (HT). It was associated with favorable clinicopathological characteristics, with no extrathyroidal extension $(p=0.002)$, lymph node metastasis 
$(p=0.04)$, and more prolonged recurrence-free survival $(p=0.001)$ [9]. However, some studies have shown contradicting results $[11-13,15]$. We did not evaluate the coexisting HT in our study. We utilized FDG PET-CT to assess these patients as it is considered an excellent method to detect recurrent disease [32].

Our study has several limitations, such as its retrospective design and the low number of patients in individual groups. Longer follow-up is needed as patients may develop recurrence at a later date. All the patients with IR did not undergo FDG PET-CT, as our center has a high FDG PET/CT threshold. We investigated only 12 patients with $\mathrm{TgAb}>500 \mathrm{IU} / \mathrm{ml}$. It may be a reason for the lower recurrence in our study. Future research with a large number of subjects is needed.

\section{Conclusion}

This study demonstrated that high post-operative $\mathrm{TgAb}$ level and lateral compartment lymph nodal metastases are the risk factor for persistent high TgAb level and incomplete treatment response in long-term follow-up. Radioiodine therapy decreases TgAb levels in a large number of patients. The low level of raised $\operatorname{TgAb}(<$ $1000 \mathrm{IU} / \mathrm{ml}$ ) is associated with an excellent outcome even with a rising TgAb level. Anatomical recurrence is noted at high TgAb levels $(>1000 \mathrm{IU} / \mathrm{ml})$ and involves the neck and thoracic region. Overall, raised TgAb was associated with good clinical outcomes and not associated with increased mortality.

\section{Abbreviations}

DTC: differentiated thyroid cancer; Tg: Thyroglobulin; TgAb: Antithyroglobulin antibody; RIT: High-dose radioiodine therapy; 18F-FDG PET-CT: [18F]Fluoro-2deoxy-2-d-glucose positron emission tomography-computed tomography

\section{Acknowledgments}

We would like to express our special thanks to all the thyroid cancer patients, their relatives, and our staff.

\section{Code availability}

Not applicable.

\section{Authors' contributions}

$\mathrm{MO}$ and SG contributed to the concept and design of the study. AHN, PM, and PKP did data collection, data, and statistical analysis. MO wrote the first draft. SB, AA, MD, and AP did manuscript preparation and image preparation. $\mathrm{MO}$ and $\mathrm{SG}$ finalized manuscript.

\section{Funding}

Not applicable.

\section{Availability of data and materials}

Available (partial) after adequate permission from the institute.

\section{Declarations}

Consent to participate

Consent for investigations and RIA obtained as per the local policies.
Ethics approval and consent to participate

The ethical committee's permission was not required as this was a retrospective study on anonymized data and that all procedures were done a part of the routine standard of care procedures.

\section{Competing interests}

None.

\section{Author details}

${ }^{1}$ Department of Nuclear Medicine, SGPGIMS, Lucknow, India. ${ }^{2}$ Department of Biostatistics and Health Informatics, SGPGIMS, Lucknow, India.

Received: 21 December 2020 Accepted: 2 April 2021

Published online: 15 April 2021

\section{References}

1. Cancer today. Available from: http://gco.iarc.fr/today/home. [cited 2020 Mar 18]

2. Haugen BR, Alexander EK, Bible KC, Doherty GM, Mandel SJ, Nikiforov YE, et al. 2015 American Thyroid Association management guidelines for adult patients with thyroid nodules and differentiated thyroid Cancer: the American Thyroid Association guidelines task force on thyroid nodules and differentiated thyroid Cancer. Thyroid. 2016;26(1):1-133. https://doi.org/10.1 089/thy.2015.0020.

3. Spencer CA. Clinical review: clinical utility of thyroglobulin antibody (TgAb) measurements for patients with differentiated thyroid cancers (DTC). J Clin Endocrinol Metab. 2011;96(12):3615-27. https://doi.org/10.1210/jc.2011-1740.

4. Verburg FA, Wäschle K, Reiners C, Giovanella L, Lentjes EGWM. Heterophile antibodies rarely influence the measurement of thyroglobulin and thyroglobulin antibodies in differentiated thyroid cancer patients. Horm Metab Res. 2010;42(10):736-9. https://doi.org/10.1055/s-0030-1254132.

5. Giovanella L, Keller F, Ceriani L, Tozzoli R. Heterophile antibodies may falsely increase or decrease thyroglobulin measurement in patients with differentiated thyroid carcinoma. Clin Chem Lab Med. 2009;47(8):952-4. https://doi.org/10.1515/CCLM.2009.230.

6. Latrofa F, Ricci D, Montanelli L, Rocchi R, Piaggi P, Sisti E, et al. Lymphocytic thyroiditis on histology correlates with serum thyroglobulin autoantibodies in patients with papillary thyroid carcinoma: impact on detection of serum thyroglobulin. J Clin Endocrinol Metab. 2012;97(7):2380-7. https://doi.org/1 0.1210/jc.2011-2812.

7. Muzza M, Degl'Innocenti D, Colombo C, Perrino M, Ravasi E, Rossi S, et al. The tight relationship between papillary thyroid cancer, autoimmunity and inflammation: clinical and molecular studies. Clin Endocrinol. 2010;72(5): 702-8. https://doi.org/10.1111/j.1365-2265.2009.03699x.

8. Jankovic B, Le KT, Hershman JM. Clinical review: Hashimoto's thyroiditis and papillary thyroid carcinoma: is there a correlation? J Clin Endocrinol Metab. 2013;98(2):474-82. https://doi.org/10.1210/jc.2012-2978.

9. Lee J-H, Kim Y, Choi J-W, Kim Y-S. The association between papillary thyroid carcinoma and histologically proven Hashimoto's thyroiditis: a meta-analysis. Eur J Endocrinol. 2013;168(3):343-9. https://doi.org/10.1530/EJE-12-0903.

10. Durante C, Tognini S, Montesano T, Orlandi F, Torlontano M, Puxeddu E, et al. Clinical aggressiveness and long-term outcome in patients with papillary thyroid cancer and circulating antithyroglobulin autoantibodies. Thyroid. 2014;24(7):1139-45. https://doi.org/10.1089/thy.2013.0698.

11. Kim KW, Park YJ, Kim EH, Park SY, Park DJ, Ahn S-H, et al. Elevated risk of papillary thyroid cancer in Korean patients with Hashimoto's thyroiditis. Head Neck. 2011;33(5):691-5. https://doi.org/10.1002/hed.21518.

12. Dvorkin S, Robenshtok E, Hirsch D, Strenov $Y$, Shimon I, Benbassat CA. Differentiated thyroid cancer is associated with less aggressive disease and better outcome in patients with coexisting Hashimotos thyroiditis. J Clin Endocrinol Metab. 2013;98(6):2409-14. https://doi.org/10.1210/jc.2013-1309.

13. McLeod DSA, Cooper DS, Ladenson PW, Ain KB, Brierley JD, Fein HG, et al. Prognosis of differentiated thyroid cancer in relation to serum thyrotropin and thyroglobulin antibody status at time of diagnosis. Thyroid. 2014;24(1): 35-42. https://doi.org/10.1089/thy.2013.0062.

14. Chung J-K, Park YJ, Kim TY, So Y, Kim S-K, Park DJ, et al. Clinical significance of elevated level of serum antithyroglobulin antibody in patients with differentiated thyroid cancer after thyroid ablation. Clin Endocrinol. 2002; 57(2):215-21. https://doi.org/10.1046/j.1365-2265.2002.01592.x.

15. Kim WG, Yoon JH, Kim WB, Kim TY, Kim EY, Kim JM, et al. Change of serum antithyroglobulin antibody levels is useful for prediction of clinical 
recurrence in thyroglobulin-negative patients with differentiated thyroid carcinoma. J Clin Endocrinol Metab. 2008;93(12):4683-9. https://doi.org/1 0.1210/jc.2008-0962.

16. Rubello D, Casara D, Girelli ME, Piccolo M, Busnardo B. Clinical meaning of circulating antithyroglobulin antibodies in differentiated thyroid cancer: a prospective study. J Nucl Med. 1992;33(8):1478-80

17. Tuttle M, Morris LF, Haugen B, Shah J, Sosa JA, Rohren E, et al. AJCC cancer staging manual. 8th ed; 2017. p. 1-19.

18. Hollowell JG, Staehling NW, Flanders WD, Hannon WH, Gunter EW, Spencer CA, et al. Serum TSH, T (4), and thyroid antibodies in the United States population (1988 to 1994): National Health and nutrition examination survey (NHANES III). J Clin Endocrinol Metab. 2002;87(2):489-99. https://doi. org/10.1210/jcem.87.2.8182

19. Feldt-Rasmussen U, Petersen PH, Date J, Madsen CM. Sequential changes in serum thyroglobulin $(\mathrm{Tg})$ and its autoantibodies ( $\mathrm{TgAb}$ ) following subtotal thyroidectomy of patients with preoperatively detectable TgAb. Clin Endocrinol. 1980;12(1):29-38. https://doi.org/10.1111/j.1365-2265.1980. tb03129.x.

20. Feldt-Rasmussen U, Bech $\mathrm{K}$, Date J, Petersen $\mathrm{PH}$, Johansen $\mathrm{K}$. A prospective study of the differential changes in serum thyroglobulin and its autoantibodies during propylthiouracil or radioiodine therapy of patients with graves' disease. Acta Endocrinol. 1982;99(3):379-85. https://doi.org/10.1 530/acta.0.0990379.

21. Feldt-Rasmussen U, Blichert-Toft M, Christiansen C, Date J. Serum thyroglobulin and its autoantibody following subtotal thyroid resection of graves' disease. Eur J Clin Investig. 1982;12(3):203-8. https://doi.org/10.1111/ j.1365-2362.1982.tb00994.x.

22. Polyzos SA, Anastasilakis AD. Alterations in serum thyroid-related constituents after thyroid fine-needle biopsy: a systematic review. Thyroid. 2010;20(3):265-71. https://doi.org/10.1089/thy.2009.0157.

23. Benvenga S, Bartolone L, Squadrito S, Trimarchi F. Thyroid hormone autoantibodies elicited by diagnostic fine needle biopsy. J Clin Endocrinol Metab. 1997;82(12):4217-23. https://doi.org/10.1210/jcem.82.12.4420.

24. Görges R, Maniecki M, Jentzen W, Sheu SN-Y, Mann K, Bockisch A, et al. Development and clinical impact of thyroglobulin antibodies in patients with differentiated thyroid carcinoma during the first 3 years after thyroidectomy. Eur J Endocrinol. 2005;153(1):49-55. https://doi.org/10.1530/ eje.1.01940.

25. Chiovato L, Latrofa F, Braverman LE, Pacini F, Capezzone M, Masserini L, et al. Disappearance of humoral thyroid autoimmunity after complete removal of thyroid antigens. Ann Intern Med. 2003;139(5 Pt 1):346-51. https://doi.org/10.7326/0003-4819-139-5_Part_1-200309020-00010.

26. Verburg FA, Luster M, Cupini C, Chiovato L, Duntas L, Elisei R, et al. Implications of thyroglobulin antibody positivity in patients with differentiated thyroid cancer: a clinical position statement. Thyroid. 2013; 23(10):1211-25. https://doi.org/10.1089/thy.2012.0606.

27. Spencer CA, Takeuchi M, Kazarosyan M, Wang CC, Guttler RB, Singer PA, et al. Serum thyroglobulin autoantibodies: prevalence, influence on serum thyroglobulin measurement, and prognostic significance in patients with differentiated thyroid carcinoma. J Clin Endocrinol Metab. 1998;83(4):1121-7. https://doi.org/10.1210/jcem.83.4.4683.

28. Bueno F, Falcone MGG, Peñaloza MA, Abelleira E, Pitoia F. Dynamics of serum antithyroglobulin antibodies in patients with differentiated thyroid cancer. Endocrine. 2020;67(2):387-96. https://doi.org/10.1007/s12020-01902112-7.

29. Soyluk O, Boztepe H, Aral F, Alagol F, Özbey NC. Papillary thyroid carcinoma patients assessed to be at low or intermediary risk after primary treatment are at greater risk of long term recurrence if they are thyroglobulin antibody positive or do not have distinctly low thyroglobulin at initial assessment. Thyroid. 2011;21(12):1301-8. https://doi.org/10.1089/thy.2011. 0122

30. Tsushima Y, Miyauchi A, Ito Y, Kudo T, Masuoka H, Yabuta T, et al. Prognostic significance of changes in serum thyroglobulin antibody levels of pre- and post-total thyroidectomy in thyroglobulin antibody-positive papillary thyroid carcinoma patients. Endocr J. 2013;60(7):871-6. https://doi. org/10.1507/endocri.EJ12-0410

31. Rosario PW, Carvalho M, Mourão GF, Calsolari MR. Comparison of Antithyroglobulin antibody concentrations before and after ablation with 1311 as a predictor of structural disease in differentiated thyroid carcinoma patients with undetectable basal thyroglobulin and negative neck ultrasonography. Thyroid. 2016;26(4):525-31. https://doi.org/10.1089/thy.201 5.0445.

32. Ozkan E, Soydal C, Araz M, Aras G, Ibis E. The additive clinical value of $18 \mathrm{~F}-$ FDG PET/CT in defining the recurrence of disease in patients with differentiated thyroid cancer who have isolated increased antithyroglobulin antibody levels. Clin Nucl Med. 2012;37(8):755-8. https://doi.org/10.1097/ RLU.0b013e31825ae77b.

\section{Publisher's Note}

Springer Nature remains neutral with regard to jurisdictional claims in published maps and institutional affiliations.
Ready to submit your research? Choose BMC and benefit from:

- fast, convenient online submission

- thorough peer review by experienced researchers in your field

- rapid publication on acceptance

- support for research data, including large and complex data types

- gold Open Access which fosters wider collaboration and increased citations

- maximum visibility for your research: over $100 \mathrm{M}$ website views per year

At $\mathrm{BMC}$, research is always in progress.

Learn more biomedcentral.com/submissions 